Scientific Review - Engineering and Environmental Sciences (2021), 30 (3), 400-410

Sci. Rev. Eng. Env. Sci. (2021), 30 (3)

Przegląd Naukowy - Inżynieria i Kształtowanie Środowiska (2021), 30 (3), 400-410

Prz. Nauk. Inż. Kszt. Środ. (2021), 30 (3)

http://iks.pn.sggw.pl

DOI 10.22630/PNIKS.2021.30.3.34

Sara Ali MUTER, Jasim H. KADHUM, Ahmed S. HASSAN

Mustansiriyah University, College of Science

\title{
Approaching of May maximum surface air temperature to characteristic summer season for Baghdad city
}

Key words: maximum air temperature, summer season, May, Baghdad

\section{Introduction}

Surface air temperature is change related to change for seasons. These changes happen in the seasons themselves, that is winter became warmer, spring becomes early and leaves quickly, and summer becomes longer and hotter. According to meteorologist research for many countries, these changes were used in reference to atmospheric variability on timescale longer than the two weeks limit of most deterministic atmospheric predictability (Bilal, Kais \& Enas, 2013). That also point to climate variability, which are the variations in the mean state and other statistics of the climate spatially and temporally, usually beyond individual weather statistics. This term "climate variability" cannot deviations of climatic statistics over a given period of time (e.g. a month, season or year), some scientist are of the opinion that this period can transcend to decades (30 years). Climate variability assessed by these deviations, which are usually termed anomalies. The variability may be due to natural internal processes within the climate system (internal variability), or to variations in natural or anthropogenic external factors (external variability), but climate variability is more affiliated to the internal variability unlike climate change (Zeki, 2017). One of the climatic elements that sensitive to climate variability is air temperature and that play significant role on the human life style. Beside that it is evidence of changing in the climate system because of the possibility of calculation this variable for both cases; temporal and spatial. Air temperature interacts with other climate elements such as atmospheric pressure, wind, evaporation, and relative humidity (Muter, 2014). 
Attributes of the seasons may vary by location, but there are still broad definitions that cross most of the boundaries. The timing and characteristics of the seasons depends upon the location on Earth. Summer, season extending from the summer solstice to the autumnal equinox, is one of the four Earth's seasons that goes after spring and foreshadows autumn. In winter, days become warm than before hot and really long, while nights in this season are the shortest. Sun shines so bright and most active, it means that everything in the nature gets a lot of energy form the sun, to support life, breeding and feeding. Summer, long days, and become hotter creates a special lifelong conditions for animals and plants activities (Chitu, Giosanu \& Matescu, 2015). Northern hemisphere is a part of the Earth that is located north to equator. Summer is the warmest season of the year occurring between spring and autumn and constituting June, July, and August. The hottest month is July, because in this time Earth gets more straight sun lights (Wang, Li \& Li, 2019).

Most previous work has focused on the spring-to-summer transition, this transition period is distinct from the winter and summer seasons and warrants further investigation. An analysis of this transition period is also expected to improve our understanding of conditions in winter and summer. Many studies have explored anomalies in temperature especially in summer. These studies have greatly enhanced our understanding of surface air temperature anomalies during summer. Recently study found out the mean air temperature increased for all months and for four seasons because of global climate change, while disagree with opinion that refer to overlap in month or season. The maximum air temperature were increased more than $1{ }^{\circ} \mathrm{C}$ for spring and summer, while less than $1^{\circ} \mathrm{C}$ for winter and autumn middle and southern Iraq (Hassan \& Alhashimi, 2018). The monthly air temperatures

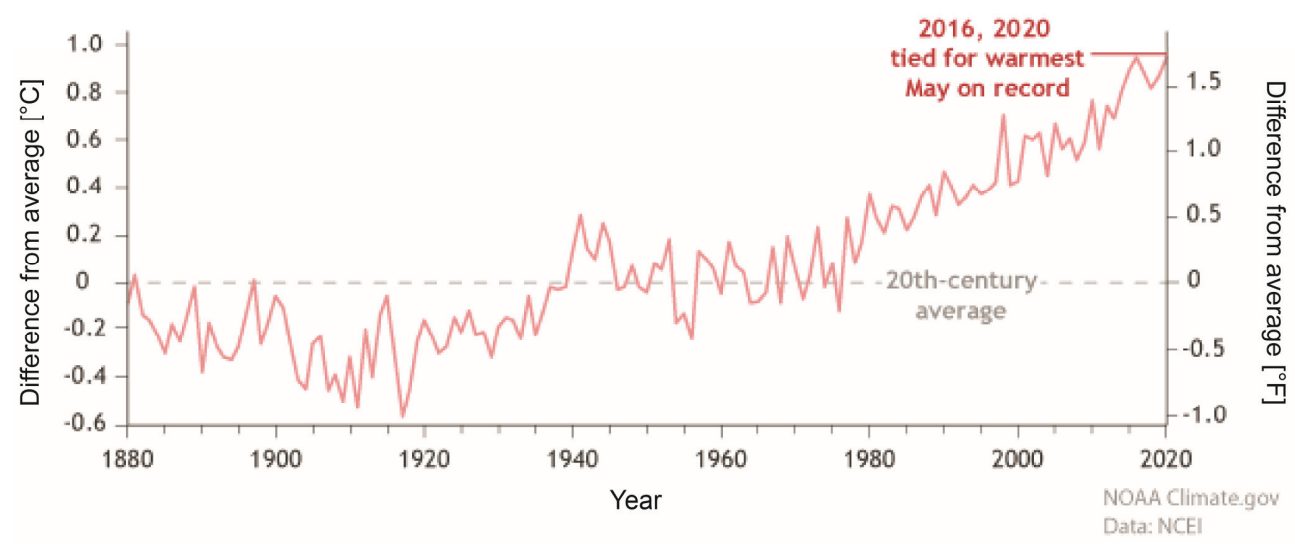

FIGURE 1. The global temperature differences from average for all Mays from 1895-2020. May 2020 tied for the warmest May on record with May 2016 (National Centers for Environmental Information NOAA National Centers for Environmental Information [NCEI], 2020) 
(maximum and minimum) recorded high increased of temperature which happened in summer, but with less force for transitional months nearby (May and September), so that May is approaching summer features for maximum temperatures (Fig. 1), and September is approaching summer features but for minimum temperatures (Muter, 2014).

The estimation of increased air temperature in the center Baghdad city and rural side beside effect of increasing population density that there was a strong tendency for a temperature increasing during July and October (Ahmed \& Hassan, 2018). Daily maximum air temperature studied for long time (2006-2017) that found 70 extreme events happen 60 of them happen in Basra. The extreme events in the end studied period were four more time than beginning studies. That found evidence for summer extended to September more than May whereas both of these months have summer characteristics (Vicente-Serrano et al., 2018). Trends of maximum air temperature exhibited a clear elevation-warming dependency, with the strongest warming recorded at highly elevated sites. For mean air temperature trends, there are no clear spatial and temporal seasonal differences across Peru (Liu, Yin, Shao \& Qin, 2006). Analysis of mean summer maximum temperature changes in frequency and intensity of daily temperature extreme temperature variability and trends over Romania which was found of maximum temperature rate $21.0 \%$ per decade. It was noted that the level of statistical significance of maximum and minimum temperature linear trends per decade was low during winter, spring and autumn. But this level of significance was very high for June, July and August months (Chitu et al. 2015).

The length of the season has been increased about 17 days during the 43-year study period. The monthly record-setting for cold events were found in the earlier part of the study period, while the warm events occurred mostly in the later half, especially since the 1990s (Wu \& He, 2017). The anomalies in the accelerated transition years display a relatively quick month-to-month change. This suggests a plausible contribution of inter-seasonal variations to the accelerated transitions (Zarenistanak, Dhorde \& Kripalani, 2014). Temperature tendencies indicated positive change in temperature, particularly in summer and spring over most of the stations. Moreover, temperature increment in winter is less in comparison with other seasons. Increasing tendencies in $T_{\min }$ were more than $T_{\max }$ in all the seasons. Therefore, the increase in annual and seasonal TM can be attributed to higher increase in $T_{\min }$. The results showed that most of the positive significant mutation points began in 1990s in the study area (World Atlas, 2021).

These work focus on provide a comprehensive picture of spring-to-summer climate variability for partially areas, and then do an investigation of the factors and processes involved in anomalies during the transition season is warranted. This study, describe monthly air temperatures for Baghdad's hot season using statistical method for maximum temperatures and understand the behavior of begin early summer and check changes in the length and the strength of Baghdad's hot season between 1970 and 2017, especially the changes that change in May. 


\section{Data and methods}

The study area is Iraq, specifically Baghdad, where Iraq geographically located in the range of sub-tropical displays in the northern hemisphere between the two latitudes $29.5-37.5$ north of the equator and longitudes $38.45-48.45$ east of the Greenwich line. Baghdad is the capital of the Republic of Iraq, shown in Figure 2. It is one of its largest cities and the second largest city in the Arab world and the second largest city in Western Asia. It is also considered the economic and administrative center in the country. Baghdad occupies a geographical position at the latitude 33.3 north of the equator and the longitude 44.4 east of the Greenwich line, this is from a spatial point of view. As for time, the study was determined by the duration of 1970-2017 (Iraqi Meteorological Organization and Seismology [IMOS], 2017).

There is in Baghdad governorate a monitoring station located in Baghdad International Airport, established since the airport's foundation and holds the global code 650 within the codes registered in the World Meteorological Organization where it works on surface monitoring, called Iraqi Meteorological Organization and Seismology (IMOS). Using the monthly data for maximum temperatures that adopted from for 47 years from 1970 to 2017 for Baghdad city. The study period was divided into two periods, the first

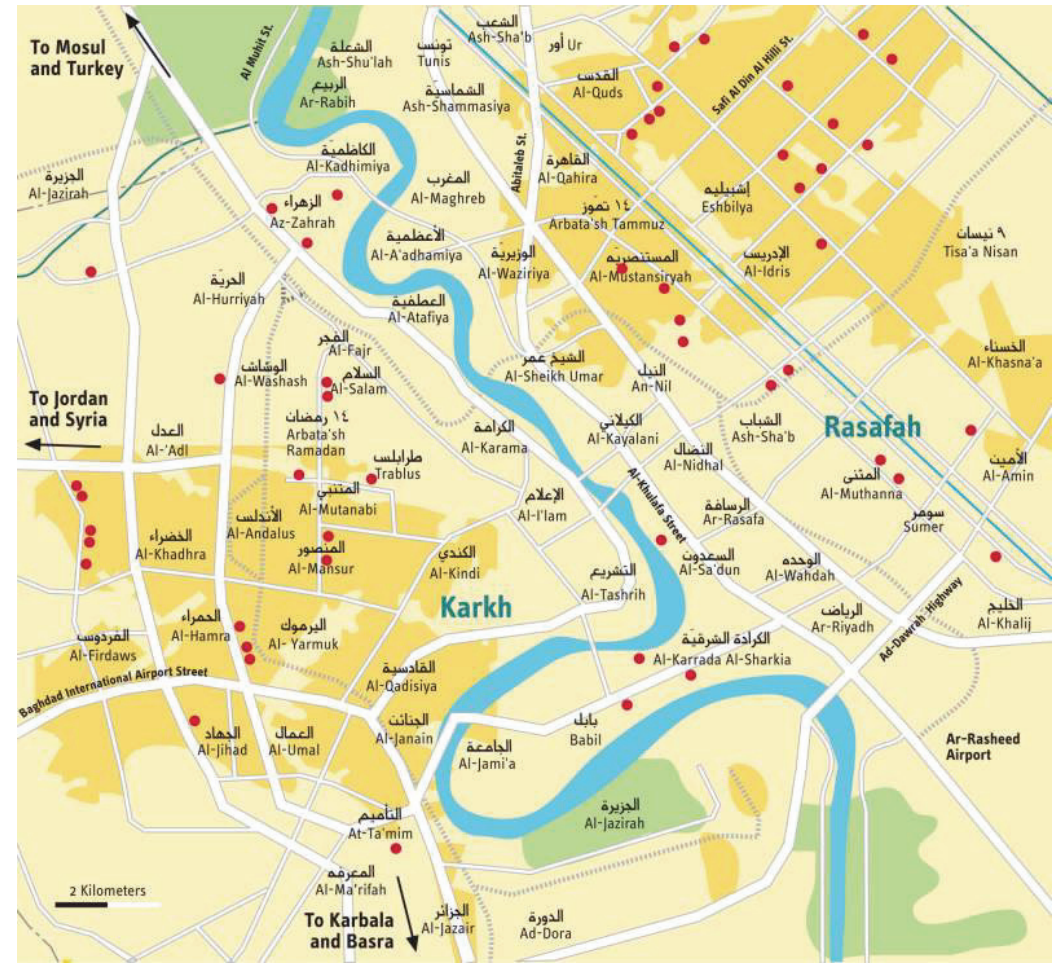

FIGURE 2. Map of the study area (Baghdad governorate) (IMOS, 2017) 
period from 1970-1991 and the second period from 1992-2017. Thirty years of data is long enough to calculate an average that is not influenced by year-to-year variability. The reason for choosing is the availability of its data and a continuation of previous research on this topic that touched on the overlap of the seasons, knowing that there are research studies of temperatures and their general direction.

\section{Results and discussion}

Objective study of observation seasonal variation to understand changes that happen in monthly air temperature with increasing daily length related with latitude more than balancing 108 the increasing solar zenith angle so that saturation increases slightly with latitude. In the case for specific region (Baghdad), this study focused on the variation for maximum air temperature in May during approaching summer properties for limit period (1970-2017). The study period was divided into two periods: the first begin in 1970, while the 1991 was the end year, and the second (1992-2017).

Due to climatic changes, all months of the year will increase in temperature, but this increase depends on two main points, which are climate variation and climate changes. When we compare the distinguished cases (the increase over the average) for the month of May and convert them into ratios compared to the months (June and July), the result indicated that the rate of increase for the month of May was $54 \%$, while the rate of increase for the months of June and July was $50 \%$ and $48 \%$, respectively. We conclude from this that May is qualified to acquire the characteristics of the summer season due to this high percentage. In addition, there should be a difference in the rates, since May approaches the characteristics of summer season, June of the beginning of the season and July the climax of the summer season.

Temperature tendencies indicated positive change in temperature, particularly in summer. Figure 3 shown time series of variation $T_{\max }$ in May, where

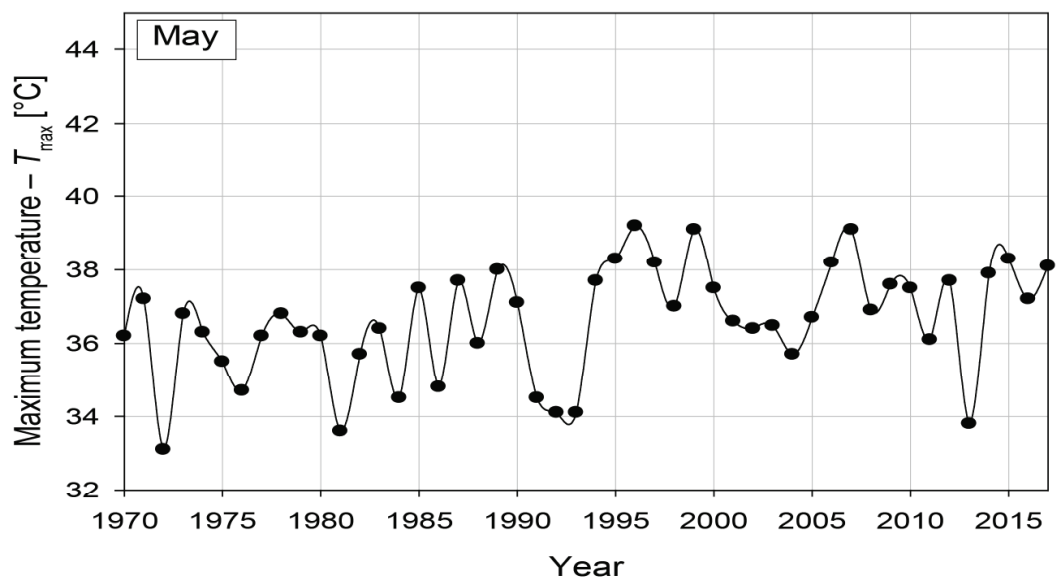

FIGURE 3. Time series for temperature maximum values in May during 1970-2017 for Baghdad city 
minimum $T_{\max }$ was $33^{\circ} \mathrm{C}$ in 1972 , and high value was $39^{\circ} \mathrm{C}$ in 2007 ; that is, the different for transfer season for May $\left(6^{\circ} \mathrm{C}\right)$. Therefore, this split came to two periods from this point and because of the $T_{\max }$. Below $38^{\circ} \mathrm{C}$ in the first period, while in the second more than seven years $(1995,1996,1997,1999,2005$, 2006 , and 2015) were above $38^{\circ} \mathrm{C}$. These results show different inter-seasonal variation between these two periods, meaning that each period has its own inter-seasonal variation. The pattern of $T_{\max }$ for each period was different too, in the first period more regular fluctuation than second period that represent each three years maximum peak.

June represented first month for summer season, and the minimum value of $T_{\max }$ was $39^{\circ} \mathrm{C}$, that is the maximum temperature for May as shown in Figure 4 , where the maximum of $T_{\max }$ was $44^{\circ} \mathrm{C}$. The inter-seasonal variation for this month was about $6^{\circ} \mathrm{C}$, although the second period has more wide variance than first period, but less than May, and this result confirms the trend in the pre- vious paragraph, which was split the period study into two parts.

The $T_{\max }$ for July behavior similar to June, which represent summer's characteristics. The minimum $T_{\max }$ was $42^{\circ} \mathrm{C}$ that the same temperature for maximum temperature for June, while the maximum temperature was $48^{\circ} \mathrm{C}$ as shown in Figure 5. The inter-seasonal variation for this month was about $6^{\circ} \mathrm{C}$. The maximum peak of $T_{\max }$ for first period was less than $46^{\circ} \mathrm{C}$, while in the second period five years was above $46^{\circ} \mathrm{C}(1996$, 2000, 2012, 2015, and 2017). This refer to general trends tends to increased $T_{\max }$.

The results that carried out when find the difference between $T_{\max }$ for June-May are shown in Figure 6. The first period characteristic of the summer season was the large number of fluctuations with same wave cycle, while the second periods have less fluctuation with short amplitude. Generally the high difference for $T_{\max }$ (June-May) was $8^{\circ} \mathrm{C}$.

The difference between July and May is shown in Figure 7. The fluctua-

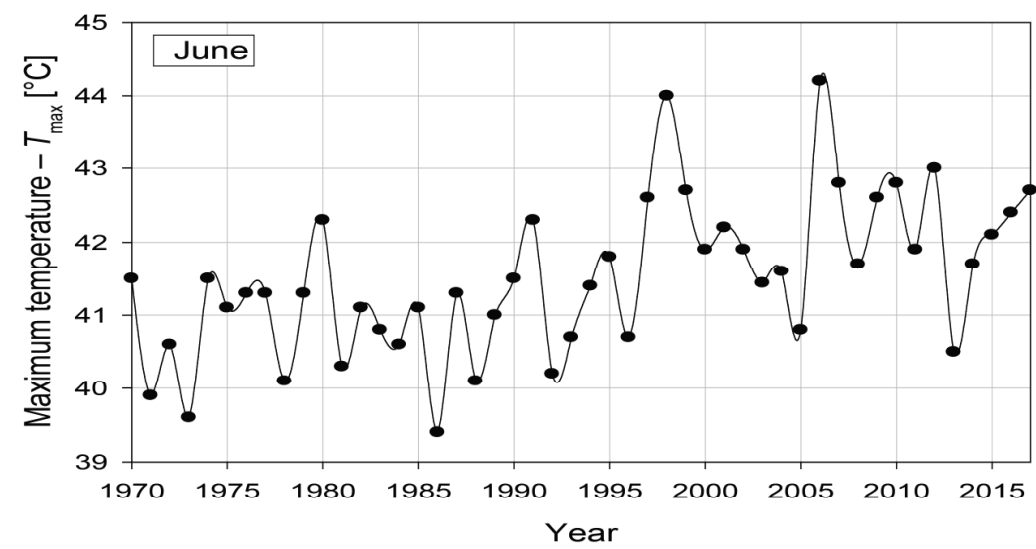

FIGURE 4. Time series for temperature maximum values in June during 1970-2017 for Baghdad city 


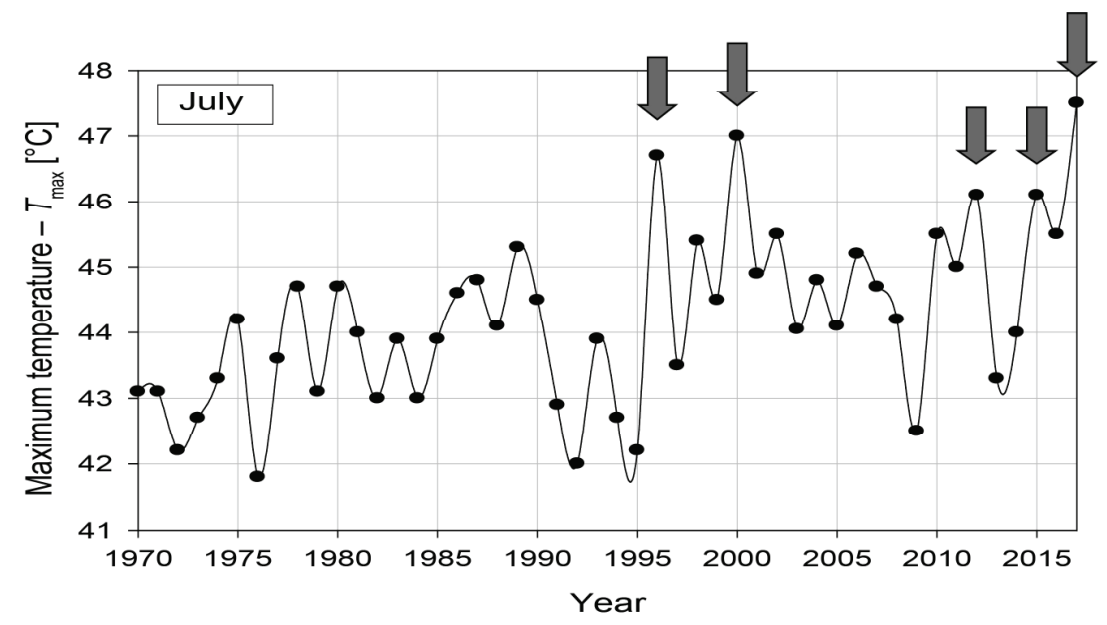

FIGURE 5. Time series for temperature maximum values in July during 1970-2017 for Baghdad city

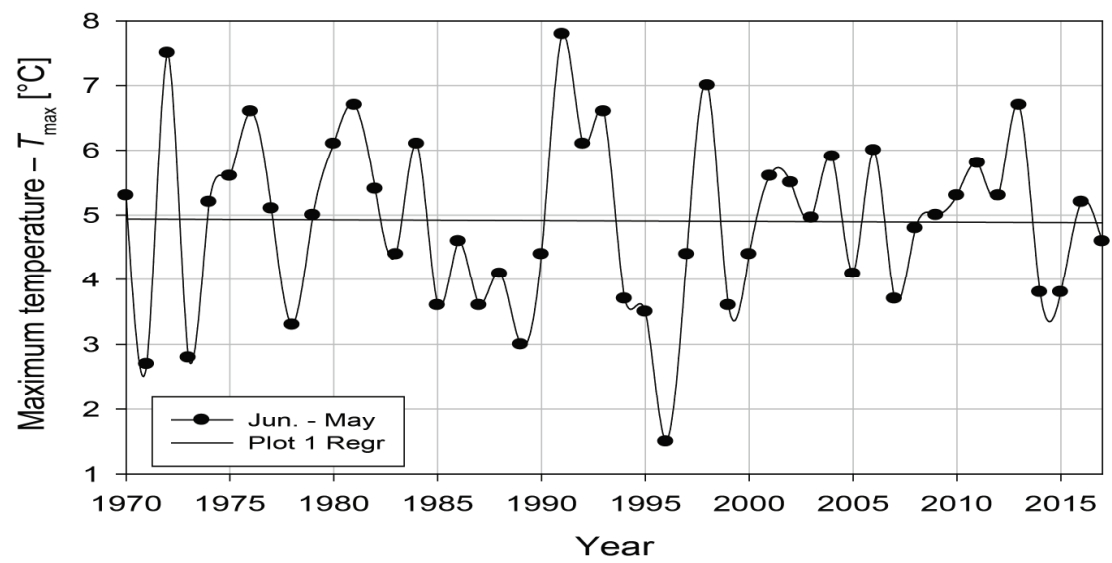

FIGURE 6. Time series for differences between temperature maximum values in June-May during 1970-2017 for Baghdad city

tion was irregular, and the variance was about $2^{\circ} \mathrm{C}$ than average with short amplitude except a few years (i.e. 1995) to represented one of the most important properties of summer, with high variance was about $6^{\circ} \mathrm{C}$.

When find the difference between two months in the same season as noted in Figure 8, the variance in the begging was $1-2^{\circ} \mathrm{C}$ then reach to $5^{\circ} \mathrm{C}$ in 1995 that were compatible with previous cases, so that May was approaching to summer.

When compare between summer's months with May in the dataset that draw in Figures 6,7 and 8. These three cases for difference of $T_{\max }$. The significant increase appear in the $T_{\max }$ during May and summer months (June, July, and August) during the study period as follows 


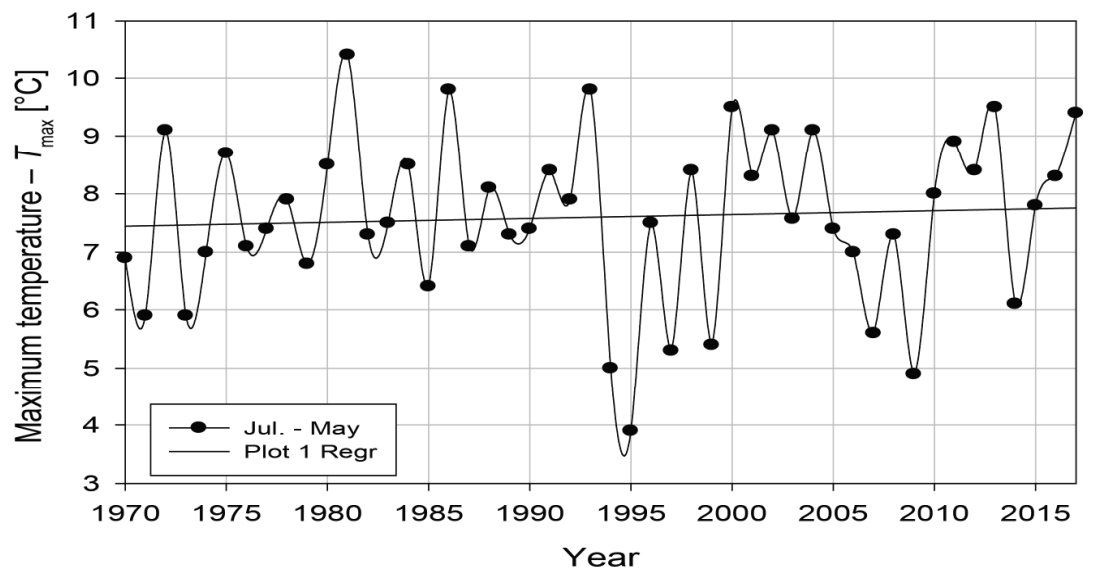

FIGURE 7. Time series for differences between temperature maximum values in July-May during 1970-2017 for Baghdad city

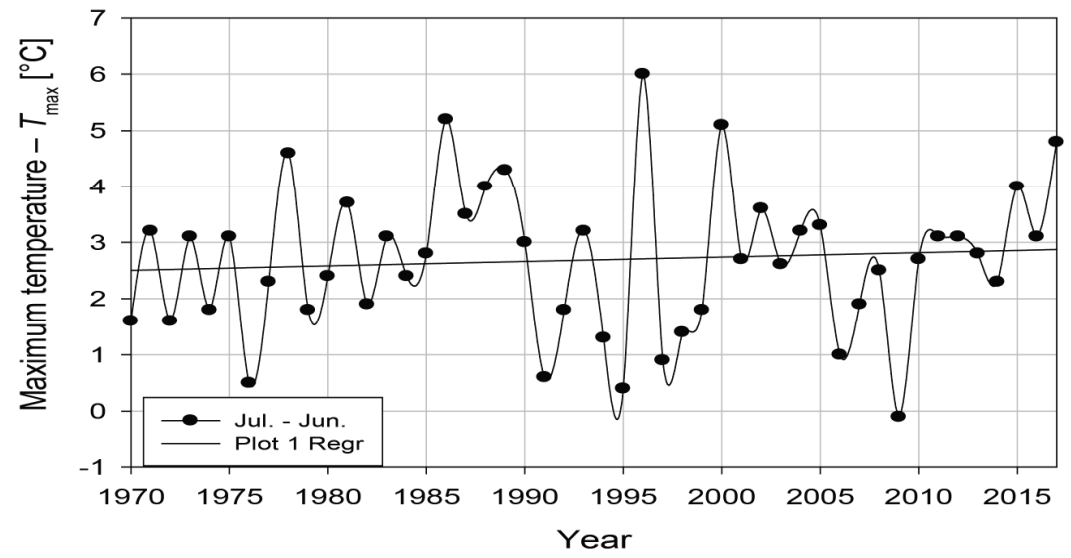

FIGURE 8. Time series for differences between temperature maximum values in July-June during 1970-2017 for Baghdad city

(1.9 for May, 1.2 for June, 4.4 for July, 4.9 for August). There is also a significant $T_{\max }$ for Baghdad with similar behavior of $T_{\max }$ in May to June and July during the second period of the study period (1992-2017), unlike the first period (1970-1991). Two phases in second period found out, the positive phase happened in 1995, 1999, and 2006, four cases were negative (1992, 2004, 2013, and 2016), while a few cases recorded in first period.

For the purpose of comparing the change for the study periods, Table 1 was adopted from Figure 7, which shows a comparison between the two periods. It is clear that the amount of difference for the first period is greater than the second period, and this indicates that the maximum temperatures are close to their 
TABLE 1. The statistics, mean for two periods of study for Baghdad

\begin{tabular}{|l|c|c|c|}
\hline Period & Start deviation at $8^{\circ} \mathrm{C}$ & End deviation at $8^{\circ} \mathrm{C}$ & Mean \\
\hline $1970-1991$ & 0.6 & 0.5 & 0.55 \\
\hline $1992-2017$ & 0.2 & 0.5 & 0.35 \\
\hline
\end{tabular}

characteristics in the summer season. Accordingly, the ratio of the difference between the temperatures of the two periods is $63 \%$.

The amplitudes of monthly variability had same distance from leaner correlation especially in 1999, and 2013, that represent coherent wave with summer seasons. The variance difference for $T_{\max }$ between May and June approximately was $2^{\circ} \mathrm{C}$ for second study's period, while exceed this range in first period. This variance change to $7.5^{\circ} \mathrm{C}$ when find difference between July and May. There is a slight geographic variation in the beginning and end of the season, so that May had characters approaching to strong summer features for the maximum temperature. The 1992 was the beginning of climate change, before 1992 May had different behavior to the summer months, but after the 1992 May was closed to the summer characteristics months through behavior point.

Standard deviation is used to find the dispersion error and standard deviation for both May and summer as shown in Table 2. Be confirmed again that May was near to summer than spring in light of seasonal variation and climate change.

\section{Conclusions}

A surface temperature data set for Baghdad have been used to study changes in Baghdad in order to examine the seasons temperature over five decades. Objective study of observation seasonal variation to understand that changes happen in monthly air temperature refer to extended daily length in summer season beside the effect of latitude. This lead to change in solar zenith angle that slightly increased. Another less effect was geographic variation in the beginning and end of the season. Significant point was summer season had extend in Baghdad to May instead of June. Since May 1992 the approaching of May was very clear because May is the first month of year when summer extend, beside May was found in spring season before 1992 according to properties of maximum temperature. The effect of Baghdad location, climate change, increased air temperature, and variation of surface air temperature lead to increased maximum air temperature for all season particularly in spring make may approaching to summer season. Before 1992 these factors

TABLE 2. Statistics characteristics for May, June, and July and the difference for Baghdad city

\begin{tabular}{|l|c|c|c|c|c|c|}
\hline Statistics & May & June & July & June-May & July-May & July-June \\
\hline Standard deviation & 1.5009 & 1.0466 & 1.3121 & 1.3310 & 1.4357 & 1.3138 \\
\hline Standard error & 0.2166 & 0.1511 & 0.1894 & 0.1921 & 0.2072 & 0.1896 \\
\hline Confidence & 0.5816 & 0.4056 & 0.5084 & 0.5158 & 0.5564 & 0.5091 \\
\hline
\end{tabular}


have less effect on maximum for Baghdad city. The inter-seasonal variation for May, June and July was about $6^{\circ} \mathrm{C}$, this mean the three months are similar in terms of the variation in maximum temperatures, and this refer to that general trends tend to increased $T_{\max }$.

The behavior of air temperature for Baghdad city during the summer months tends to increase despite the fluctuations between the increase and decrease. Such observations are consistent with global trends in temperature. The results indicate the possibility of confirming the overlap of May within the summer season through the minimum temperatures of Baghdad city and the rest of the Iraqi cities. After 1992 results revealed a significant $T_{\max }$ for Baghdad during period of 1992-2017 shown that the similar behavior of $T_{\max }$ in May to June and July; on the contrary that first period (1970-1991). The variance difference for $T_{\max }$ between May and June approximately was $2{ }^{\circ} \mathrm{C}$ for second study's period, while exceed this range in first period. This variance change to $7.5^{\circ} \mathrm{C}$ when find difference between July and May. Standard deviation is used to find the dispersion error and standard deviation for both May and summer. Be confirmed again that May was near to summer than spring in light of seasonal variation and climate change.

\section{Acknowledgements}

The authors would like to thank Mustansiriyah University (www.uomustansiriyah.edu.iq) Baghdad- Iraq for its support in the present work and Iraqi Meteorological Organization and Seismology (IMOS) for providing observed data.

\section{References}

Ahmed, E.S. \& Hassan, A.S. (2018). The impact of the extreme air temperatures on the characteristics of Iraq weather. Iraqi Journal of Agriculture Sciences, 59(2), 1139-1145.

Bilal, D.A., Kais, J.A. \& Enas, A.H. (2013). Air temperature Trends in Baghdad, Iraq for the Period 1941-2000. International Journal of Scientific and Research Publications, 3(9), 1-5.

Chitu, E., Giosanu, D. \& Mateescu, E. (2015). The variability of seasonal and annual extreme temperature trends of the latest three decades in Romania. Agriculture and Agricultural Science Procedia, 6, 429-437.

Hassan, A.S. \& Alhashimi, A.K. (2018). Effect of increasing population density on air temperature for Baghdad City. Al-Mustansiriyah Journal of Science, 29(1), 9-14.

Iraqi Meteorological Organization and Seismology [IMOS] (2017). Climate data for Baghdad Governorate Ministry of Transport 1970-2017. IMOS Climate Section [unpublished data].

Liu, X., Yin, Z.Y., Shao, X. \& Qin, N. (2006). Temporal trends and variability of daily maximum and minimum, extreme temperature events, and growing season length over the eastern and central Tibetan Plateau during 1961-2003. Journal of Geophysical Research: Atmospheres, 111(D19). https://doi. org/10.1029/2005JD006915

Muter, S.A. (2014). Variability of daily maximum and minimum temperature for summer seasons in Baghdad City (master thesis). Mustansiriyah University, Baghdad.

National Centers for Environmental Information [NCEI] (2020). Climate at a Glance: Global Time Series [database]. Retrieved form: https://www.ncdc.noaa.gov/cag

Vicente-Serrano, S.M., López-Moreno, J.I., Correa, K., Avalos, G., Bazo, J., Azorin-Molina, C., Dominguez-Castro, F., El Kenawy, A., Gimeno, L. \& Nieto, R. (2018). Recent changes in monthly surface air temperature over Peru, 1964-2014. International Journal of Climatology, 38(1), 283-306.

Wang, F., Li, Y. \& Li, J. (2019). Spatiotemporal characteristics of the dominant modes of surface air temperature interannual varia- 
tions over south China during the spring-to-summer transition. Atmosphere, 10(2), 65. https://doi.org/10.3390/atmos10020065

World Atlas (2021). Free download printable political and physical maps of the world, world map satellite. Satellite 3rd Interative World map, Baghdad City map. Retrieved from: http://world-map1.org

$\mathrm{Wu}$, R. \& He, Z. (2017). Two distinctive processes for abnormal spring to summer transition over the South China Sea. Journal of Climate, 30(23), 9665-9678.

Zarenistanak, M., Dhorde, A.G. \& Kripalani, R.H. (2014). Trend analysis and change point detection of annual and seasonal precipitation and temperature series over southwest Iran. Journal of Earth System Science, 123(2), 281-295.

Zeki, Kh.N. (2017). Effect of maximum air temperature on the monthly average temperature and the comfortable of human in Baghdad Station. College of Education Journal, 2(2), 389-407.

\section{Summary}

Approaching of May maximum surface air temperature to characteristic summer season for Baghdad city. Seasonal variability is the complex non-linear response of the physical climate system. There are two types of natural variability: those external and internal to the climate system. In any given season, natural variability may cause the climate to be different than its long-term average. This study examines with the seasonal variation of the maximum temperatures during the summer season. In addition, the maximum temperatures in May become close to the characteristics of the summer season. The monthly data for maximum temperature of May, June and July were used from Iraqi Meteorologi- cal Organization and Seismology (IMOS) for 47 years from 1970 to 2017 for Baghdad city. This period was long enough to estimate the range of approaching maximum temperature $\left(T_{\max }\right)$ May to summer. Results revealed a significant $T_{\max }$ for Baghdad during the second period (1992-2017) and shown similar behavior of $T_{\max }$ in May to June and July; on the contrary that first period (1970-1991). In second period, two phases have been found out, positive phase and negative phase. The positive phase were happened in 1995, 1999, and 2006, and the negative phase was four cases $(1992,2004$, 2013, and 2016), while a few cases recorded in first period. The amplitudes of monthly variability had same distance of leaner correlation especially in 1999 and 2013 that represent coherent wave with summer seasons. The variance difference for $T_{\max }$ between May and June approximately was $2{ }^{\circ} \mathrm{C}$ for second study's period, while exceed this range in first period. This variance change to $7.5^{\circ} \mathrm{C}$ when found difference between July and May.

\author{
Authors' address: \\ Sara Ali Muter - corresponding author \\ (https://orcid.org/0000-0002-6728-9609) \\ Mustansiriyah University \\ College of Science \\ Department of Atmospheric Sciences \\ Palestine Street, 14022 Baghdad \\ Iraq \\ e-mail: sara.a.atmsc@uomustansiriyah.edu.iq \\ Jasim H. Kadhum \\ Ahmed S. Hassan \\ Mustansiriyah University \\ College of Science \\ Department of Atmospheric Sciences \\ Palestine Street, 14022 Baghdad \\ Iraq
}

